\title{
Global Quality Management Systems: Strategies in a Challenging, Complex Environment of Mergers, Acquisitions, and Strategic Partnerships
}

\author{
Aviva Bashan ${ }^{1, ~ *, ~ A l o n ~ B e n ~ J a c o b ~}{ }^{2, ~ * ~}$ \\ ${ }^{1}$ The School of Industrial Engineering and Management, Afeka Tel Aviv Academic College of Engineering, Tel Aviv, Israel \\ ${ }^{2}$ College of Management and Technology, Walden University, Minneapolis, the United States
}

Email address:

aviva200@netvision.net.il (A. Bashan), abjacobdba@gmail.com (A. B. Jacob)

*Corresponding author

\section{To cite this article:}

Aviva Bashan, Alon Ben Jacob. Global Quality Management Systems: Strategies in a Challenging, Complex Environment of Mergers, Acquisitions, and Strategic Partnerships. American Journal of Management Science and Engineering. Vol. 6, No. 4, 2021 , pp. $103-116$. doi: 10.11648/j.ajmse.20210604.14

Received: July 22, 2021; Accepted: August 4, 2021; Published: August 12, 2021

\begin{abstract}
The relative newness of globalization processes means that insights into the complexities of management systems operating in a global environment are yet to mature. No single definition for global quality management systems (QMS) has been accepted in the literature, and there is a dearth of systematic research, models and methodologies for dealing with the complex challenges posed by globalization. These challenges are further compounded when organizations use business and strategic processes such as mergers, acquisitions, and strategic partnerships to accelerate growth. This article fills a gap in the field of global QMS development in light of these processes, and presents a preliminary attempt to develop theories and methods for analyzing global QMS in the dynamic field of mergers, acquisitions, and strategic partnerships. Data was collected from intensive field research concerning the development processes of 18 multinational companies over three years. Grounded Theory methodology was used for developing a nascent theory, a starting point not only for further research but also for developing a global QMS strategy, which is currently conspicuous in its absence. Key variables that influence the work environment, constraints, interfaces, and goals of a global QMS were formulated by reviewing the development processes of the participating multinational companies, and identifying the theoretical, practical, and gaps of leading strategic, operational, and marketing characteristics and needs generally and specifically of the QMS as related to M\&A. The themes articulate the significant issues and challenges that global QMS face following M\&A and can serve as a preliminary skeleton for constructing a body of knowledge concerning the proactive perception of the conduct of a global quality system experiencing the challenges of M\&A and global expansion. This article lays a potential foundation for broader and deeper research on a nascent theory, that will be able to guide global QMS functions in dealing with the dynamic process of mergers, acquisitions, and strategic partnerships. The impact assessment serves as a tool for identifying and developing the proper QMS integration strategy, thereby helping plan global QMS strategy and identifying the steps necessary for its effective implementation. Integration of strategic, operational, marketing, and QMS assessments before conducting the merger and acquisition (M\&A) augments the functional level of management and supports developing a strategy for integrating the global QMS in the acquired company.
\end{abstract}

Keywords: Globalization, Quality Management System (QMS), Strategic Management, Mergers and Acquisitions (M\&As), Multinational Organizations, Strategic/Operational/Marketing Relatedness, Integration

\section{Introduction}

The current paper presents field research findings on QMS in global organizations, a managerial field with little prior research and thus may be considered a "nascent theory." The study's main goal was to fill gaps in knowledge about the development processes of global QMS and how multinational companies (MNC) with multiple interfaces and processes, operate in a competitive, dynamic, and changing market. To that end, we conducted extensive field research in 
18 MNCs to investigate their global QMS processes during these global changes.

Globalization processes alter the operational environment by introducing new processes and products that cross boundaries and national borders, posing new challenges for quality managers at all levels [1]. The classic issues of local operations remain relevant, but global operations raise new concerns about the worldwide distribution of production, procurement, marketing, management, and other functions. All of these variables affect quality management. Srinivasan and Kurey defined the complex global environment of the twenty-first century and the need to change how quality management is implemented and understood [2]. Their depiction emphasizes the interdependence of production, product, service, and network processes. Recent years show an increasing trend towards companies using M\&A as a quick way to achieve new client relations and projects needed for revenue growth [3].

According to other scholars, globalization provides numerous opportunities while also posing significant challenges [4]. Fifty years ago, businesses were largely localized and served more stable markets; today, advances in communications and transportation have not only facilitated the acceleration of global corporate expansion but also spurred more intense competition and economic growth.

The early stages of this study included a review of the literature on the concept of QMS, the M\&A process, and the strategies used to achieve a successful M\&A process. The researchers discovered no existing quality management concepts that adequately cover the dynamics of change in the global market during the review. Global quality management (GQM) has not been the subject of systematic research, and there is no organized model or accepted methodology for GQM that adequately addresses the challenges confronting global organizations today.

Although GQM is a natural result of global operations and production management, it lacks a clear definition and has not been thoroughly researched [5]. Perceptions of the role of quality management in a competitive global market are still hazy. Senior executives may not understand the dynamics of a company's global expansion and the implications for the quality system's operational functioning. The limited research on the subject and the lack of a methodology or model relating to the issue highlight the need for in-depth field research into people active in the globalization and M\&A fields. Participants in the study included corporate executives, particularly quality and global operations managers in multinational corporations with ongoing managerial responsibility for global quality management and risk reduction, and those who deal with quality management in integrated and complex chains of processes, suppliers, and customers.

This article is the first step in developing a body of knowledge and formulating a theory about global QMS and methodology for dealing with the dynamic process of mergers, acquisitions, and strategic partnerships. Because of the scarcity of prior research, this field is considered a "nascent theory" that necessitates mapping the theoretical, practical, and gaps of leading strategic, operational, and marketing characteristics and needs in general and specifically of the QMS as relates to M\&A.

\section{Literature Review}

\subsection{Quality Management}

Businesses in the twenty-first century need to cope with a global environment that is complex and changing continually. They must operate successfully and find ways to grow the company; often they acquire other companies for this purpose. $\mathrm{Yu}$ and Huo noted that quality management (QM) has always been a crucial component of companies' efforts to gain a competitive advantage [6]. According to Biji et al., a quality management system (QMS) consists of a group of policies, processes, and procedures that an organization follows to improve capabilities and reliably achieve performance goals [7]. To satisfy the organization's need to grow and expand, the quality management has continuously widened its perspective from considering "what" is done to "how" it is done [8]. Parallel to companies' need to cope with the increasingly complex global environment, QM processes have grown significantly. The literature on Global Quality Management (GQM) shows increased use of this term. Still, the inconsistency in its definition and underlying philosophy highlights the need for intra-organizational coordination and process management.

Companies continually explore ways to expand their footprint beyond their current locations and look for global market opportunities. Sadeghi Moghadam et al. noted that the force of global competition has increased the general need to improve processes' quality [9]. It helped in the formation of the International Standards Organization (ISO), Deming prize, American Society for Quality (ASQ), and the broader body of knowledge such as Total Quality Management (TQM). Structured organizations and processes support the formation, standardization, and stability of the QM. According to Schönreiter, QM describes the required processes, responsibilities, and resources needed to ensure high-quality organizational activities [10]. When considering dynamic strategies such as M\&A, it is important to have standardized processes as suggested by QM concepts.

\subsection{Mergers \& Acquisitions}

Business leaders continually look for ways to increase their business size, market share, product line, and profitability [11]. Some companies use their internal resources to gain better control of project timelines and deliverables. Others use inorganic growth methods, such as M\&A, the combination of two organizations into a single organization [15]. M\&A may result in new products, new services, and access to new clients, facilitating a rapid increase in the sales and projects needed for revenue growth [3]. In 2020, over 45,000 M\&A transactions were completed globally, with a total value of $\$ 2.83$ trillion, $\$ 1.18$ trillion in the USA alone [13]. The value of M\&A deals 
is steadily growing, from $\$ 1.24$ trillion in 2002 to $\$ 2.83$ trillion in 2020. However, Ben Jacob indicated that between 70 to 90 percent of the M\&A deals fail to deliver the acquirers' expected value [14]. There is extensive literature looking at factors that can contribute to this failure rate.

The increasing trend of M\&A transactions, along with the high failure rate of this process, makes it urgent for researchers to seek the reasons for these outcomes, and explore ways to improve the success rate of M\&As. One of the factors identified as contributing to the success of M\&A is effective leadership. Indeed, effective leadership supports active collaboration, commitment and can improve M\&A outcomes [15]. Other factors influencing the M\&A outcomes are communication, culture, relationship creation, and an effective integration process [14].

As the M\&A process is dynamic and entails uncertainties, it is essential to identify factors that can support process stability during M\&As. Establishing a relationship between the acquired company and the acquiring company can bring collaboration and open communication. Creating a robust relationship can generate value and improve the success rate of the M\&A [16]. Successful acquiring companies were closer to the target companies, and there was more trust, accountability and involvement between the two integration teams. Enabling effective collaboration and trust are essential, because M\&A transactions are global and include cultural, behavioral, and other factors that may impact the M\&A outcomes.

The M\&A process is extensive and detailed to ensure that all available information is reviewed before proceeding with the acquisition. Some elements are common to all M\&A transactions, including strategy development, systematic selection and screening of possible targets, due diligence, negotiations, and integration [17]. As M\&A is a strategic way to expand, companies look into global opportunities to grow and gain a competitive advantage. Recent industry trends show an increase in cross-border M\&A as a path to gain financing from external sources for growth and expansion. There are five motivations for cross-border M\&A: value creation, improvement in efficiency, market leadership, marketing and strategic reasons, and synergistic gains [18]. Global expansion into geographical areas beyond the local system gives rise to an international operations system - an array of products and processes at disparate locations that exhibit varying dependence relations. The acquisition of a target company and its integration into a global company typically brings the need to move from local to a global QM [19].

\subsection{Quality Management and $M \& A$}

The increasing trend towards M\&A transactions led to a need to develop robust processes for improving the success rate. The integration aspect of the M\&A process become the focus of increased attention, and its importance was highlighted as a key factor for success. The integration process refers to combining the target company's functions such as quality, operations, human resources, and finance with the acquiring company's structure and methods.
Integrating QMS and supply chain management (SCM) can also play a role in achieving a competitive advantage [6]. $\mathrm{QM}$ is an essential factor for a company's success and entrance to the markets and should be adopted to improve competitive power and quality product [20]. Others have analyzed how QMS operate in global companies and suggested a framework for classifying the system's features based on global operations and marketing structures resulting from expansion processes, and found that M\&A produces network structures with multiple interrelations in highly complex and challenging constellations [21]. Therefore, it is necessary to plan relevant integration mechanisms for all quality functions. Prior research has demonstrated the need for a systems approach in global quality management, which may help face the challenges of the M\&A complexities [22].

The above literature review presented the trend in globalization and the process that supports this expansion, in addition to the quality systems, processes, and tools. The many studies surveyed showed the despite constant need for companies to expand grow their business, including through M\&A, there remains a shortage of processes that can connect the three strategies that drive growth in the industry globalization, QMS, and M\&A.

\section{Methodology}

The current research focuses on managing global quality management systems (QMS) in a challenging and complex international arena. The absence of previous research on this topic accentuates the importance of the work while also posing a challenge for verifying its quality.

The internal consistency of research questions, research design, and theoretical contributions is a critical component of methodological compatibility [23]. The findings of prior studies must be considered when selecting a research method. The methodological model for ensuring compatibility incorporates three archetypes: mature, intermediate, and nascent theories. Nascent theory is the preferred archetype for researching topics on which there is little prior theory, research, or formal theorizing. The model further specifies that qualitative methods are the most appropriate for examining nascent theories, specifically field observations, interviews, and gathering primary documents and materials. As apparent from the literature review above, GQM is indeed a nascent field, and therefore the current study used qualitative methods.

The grounded theory methodology was used to clarify the nascent theory and identifying key variables [24]. Grounded theory is exceptionally compatible for developing theories in non-linear, multidimensional situations, such as global management. Following this complex, iterative process, researchers first proposed generative questions to guide their research and reveal emerging data patterns. As additional data is collected, core concepts are formulated, and connections between the data and theoretical core concepts are drawn. The concluding stages are content analysis, verification, and summation. 
Grounded theory was not only the primary interpretive tool used in this study, it was also the basis for presenting the findings [25]. The iterative process [26] was constructive for differentiating between the global and local needs of the QMS, defining activities designed to regulate the system for achieving global quality value and identifying gaps in the system.

Data was generated from interviews, observations, and focus groups, as described below. Concurrent data collection and analysis included initial coding and category identification, followed by the storyline and theoretical coding, using the descriptive analysis and interpretation method [27] and constant comparative analysis [24]. The latter was developed as an application of the grounded theory methodology and is an iterative, analytical process for data collection, identification, coding of incidents, and combining codes into categories [24, 28, 29].

The method of descriptive analysis and interpretation method [27] demands that interpretations arise from the data, such that the relevance of the conclusions to the context and observations of the participants is apparent [30, 31]. The continuous, cyclical interaction between descriptions,

\section{Data Gathering}

Pilot study in three multinational companies
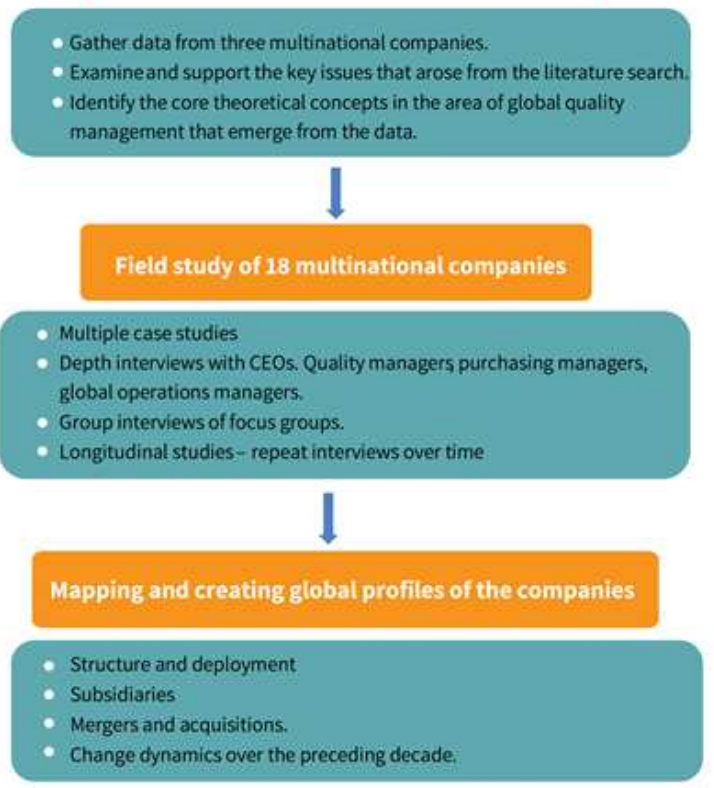

interpretations, and the collected data form a dialectical process that is continued until the general meaning structures are saturated [31]. Any proposed perception is processed (even as adjustments are made) according to the mutual responses of the participants and the researcher. Theoretical profiles of local and global quality systems, as functional response mechanisms, were constructed using this process.

The themes presented by Bashan and Armon were used for the initial analysis, and the current findings were used to re-evaluate those prior conclusions [19]. The final phase, advanced mapping, begins with combining similar groups into primary categories. Connections are then drawn between categories to focus on the relationships between them, as a means for understanding the interdependencies between categories.

The methodological steps, based on grounded theory, as implemented in this study are shown in Figure 1. The figure portrays the main stages in the data analysis process and their potential periodicity. Data analysis is often cyclical because the acquisition of additional findings can force the revision of previously drawn distinctions and augment the feedback between the data and the emerging information.

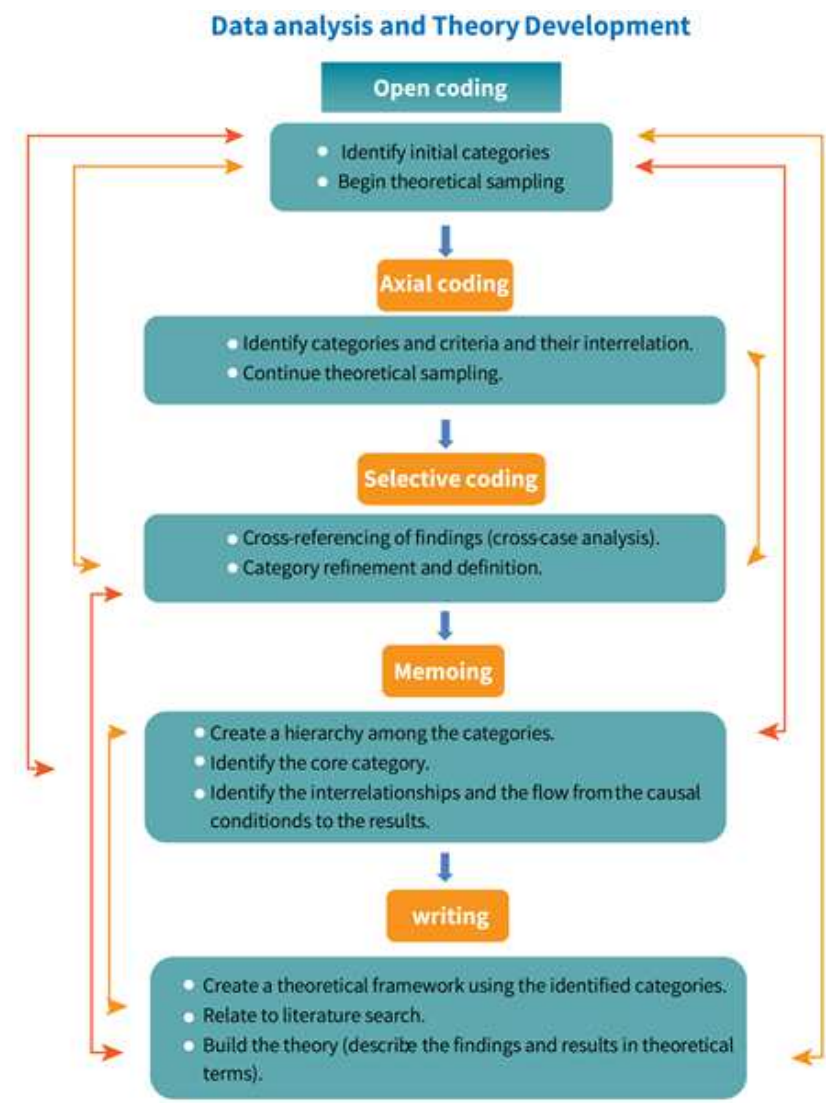

Figure 1. The methodological steps.

A systemic perspective, along with qualitative research, is essential for analyzing a phenomenon as complex as the global competitive markets created by global M\&A. In complex markets, the relationships between the many, varied actors cannot be quantified or described using the standard, static mathematical analysis tools [32]. Systemic analysis of multidimensional GQM is also supported by network theory and complex systems theory open systems theory, which has been found relevant for analyzing MNCs.

The data analyzed in this study was collected using observation, content analysis, and in-depth interviews with CEOs, quality managers, and global managers from 18 
multinational companies. All participating companies have an international footprint, are included in Fortune's list of the World's Most Admired Companies, and use continual M\&A to increase their inorganic growth. The companies were chosen using three additional criteria:

1) Fit the definition of multinational companies, as found in current literature.

2) Includes representation of both parent companies and subsidiaries. Of the 18 participating MNCs, 11 were parent companies, and 7 were subsidiaries. Other constraints on the research hampered recruiting an equal number of parent companies and subsidiaries. Still, balance was maintained by adjusting the number of interviewees from each company (see below in the section describing the interviews).

3) MNCs with broad international deployment, involved in production, development, and outsourcing, in a wide range of industries, including - but not limited to computerized communication systems, electro-optical technologies, food, high-end security, information mining, medical, pharmaceuticals, power plants, security, semiconductors, software-based analytical solutions, and telecommunication.

Triangulation was used to validate all findings. No results were included unless they were obtained from three or more sources. Triangulation also facilitates generalizing from the current sample to a larger general population [33-35]. Data was gathered over three years, using the following tools:

1) In-depth interviews with 39 VPs Global Operations and VPs Quality in parent companies and subsidiaries; some participants were interviewed more than once. All interviewees were involved in quality management, directly or indirectly, on the strategic and day-to-day tactical levels. In total, 60 interviews, lasting more than 90 minutes each, were conducted. Nearly balanced representation of parent companies and subsidiaries was achieved by conducting 32 interviews with people working in parent companies and 28 workings in subsidiaries. Returning to the same interviewees later helped us examine the dynamics of change in the global environment and its bearing on global quality management. Major topics in the interviews included:

a) Key areas and processes for which the Global Quality Manager is responsible;

b) Distinctions between global and local levels of activity, as relevant to corporate quality management;

c) The transition from a local company to MNC and the resultant changes in the needs and functions of the quality system;

d) Most significant challenges faced by global quality management;

e) How the dynamics of M\&A and strategic partnerships influence the global quality system;

f) Proposal for developing an innovative approach to address the needs of a fully functional quality system in an MNC.

2) Multiple case studies. Case studies based on two or more cases, which function in a very similar circumstances, are an optimal method for studying contemporary phenomena [36]. This obliges the researcher to observe the situation from varied perspectives and facilitates extensive cross-referencing of data. The current study, as noted, focuses on 18 MNCs and examined scenarios related to their global expansion process, the challenges expansion presented to the quality system, and the company's conduct in response to these challenges.

3) Focus group. Six global quality VPs, from different companies, formed an expert panel that met three times for 3.5 hours each time. They discussed key global quality management issues from diverse angles and perspectives. Through the forum, we obtained additional data beyond that derived from the interviews. We had an opportunity to cross-reference information while engaging in discussion and knowledge sharing, which contributed to refining the research conclusions.

4) Documentation. Data were extracted from various documents, especially minutes of meetings about improving the global quality system and the participating MNCs' operating system.

A "global profile" for each participating MNC was built on the foundation of the entire body of detailed information gathered. This article concentrates on only two components: objective information about the MNCs and their M\&A history; and interviews that explicitly referred to the challenges this presented to their QMS.

\section{Results}

The dynamic expansion of an organization through mergers, acquisitions, and strategic partnerships has been identified in previous studies $[14,19,21,22]$. It has significant impact on the complexity of the multinational company and how its functional systems perform. The findings of these studies emphasize that those aspects of M\&A related to combining the quality systems of the acquired companies and creating of integration mechanisms to ensure their combined functioning as a single organizational entity are insufficiently examined.

As a result, we expanded on the existing research and deepened the theoretical development that focuses on the desired functioning of the quality system in the face of the central challenge of mergers, acquisitions, and global expansion. The dynamics of M\&A change the structure of the operating environment and require a strategic response from the global quality system, which is not defined by a clear perception. The current findings deepen our understanding using two 2 additional analytical channels:

1) Expanding and deepening the theoretical profile of the quality system while focusing on its required response to the challenges of M\&A. We constructed a theoretical outline as an index for comparing and evaluating the findings of the field research.

2) Analyzing the degree of adequacy/gap between the field study findings and the theoretical response profile 
constructed by the researchers in stage 1 . This analysis is used to measure the reference and present the existing situation versus a required theoretical position.

Table 1 summarizes, in theoretical and practical terms, the gaps between leading strategic, operational, and marketing characteristics of QMS and actual needs, as related to M\&A and more generally.

Table 1. Characteristics of QMS.

\begin{tabular}{|c|c|c|c|}
\hline \# & $\begin{array}{l}\text { Strategic, operational, and marketing } \\
\text { characteristics (research results) }\end{array}$ & $\begin{array}{l}\text { Features of the desired QMS (theoretical } \\
\text { profile) }\end{array}$ & $\begin{array}{l}\text { Functions required of QMS facing } \\
\text { challenges of M\&A (as part of the } \\
\text { theoretical profile) }\end{array}$ \\
\hline 1. & $\begin{array}{l}\text { The global environment is characterized by } \\
\text { dispersion in diverse markets and geographical } \\
\text { regions. Multiple competitors employ various } \\
\text { strategies, and customers apply pressure to } \\
\text { have their particular needs met. As part of their } \\
\text { competitive strategy, companies must respond } \\
\text { to global demands and specific local demands. }\end{array}$ & $\begin{array}{l}\text { Numerous globally-distributed competitors and } \\
\text { customers require that operational management } \\
\text { systems (including QMS) develop the ability to } \\
\text { respond both globally and to unique, local needs } \\
\text { of each country and region. }\end{array}$ & $\begin{array}{l}\text { Keeping the local operating activity of an } \\
\text { acquired company: suppliers, customers, } \\
\text { local regulations while integrating into the } \\
\text { global operating system }\end{array}$ \\
\hline 2. & $\begin{array}{l}\text { The more diverse the markets (environments) } \\
\text { in which subsidiaries are distributed, the } \\
\text { greater the need for a global-oriented response. }\end{array}$ & & $\begin{array}{l}\text { Soft absorption of the acquired quality } \\
\text { systems, in order not to shock their existing } \\
\text { activity. }\end{array}$ \\
\hline 3. & $\begin{array}{l}\text { There is an identifiable business approach } \\
\text { focused on the characteristics of the } \\
\text { competition in each country. }\end{array}$ & $\begin{array}{l}\text { Each subsidiary must operate an independent } \\
\text { QMS. Quality assurance mechanisms are adapted } \\
\text { to customers' demands, local regulations, and } \\
\text { regional competitors. }\end{array}$ & $\begin{array}{l}\text { Integration of the acquired quality system } \\
\text { into the global processes, and adjusting the } \\
\text { guidelines provided by Corporate Quality }\end{array}$ \\
\hline 4. & $\begin{array}{l}\text { Managerial and operational decisions are } \\
\text { decentralized at the business unit level to } \\
\text { enable adaptation to the market needs }\end{array}$ & $\begin{array}{l}\text { Each QMS operates as part of the group while } \\
\text { also being granted independence. Minimal } \\
\text { coordination does not interfere with proper } \\
\text { functioning. }\end{array}$ & $\begin{array}{l}\text { Identify gaps in the acquired quality system } \\
\text { relative to the other quality systems in the } \\
\text { group. Define a process for upgrading its } \\
\text { quality infrastructure }\end{array}$ \\
\hline 5. & $\begin{array}{l}\text { Considerable attention is paid to customers' } \\
\text { diverse needs and wishes, market conditions, } \\
\text { local regulations, legal and political institutions, } \\
\text { and social norms, which vary by country. }\end{array}$ & $\begin{array}{l}\text { The customers' concept of quality varies and is } \\
\text { very dynamic; the company must accommodate } \\
\text { this dynamism using local capabilities and } \\
\text { flexibility. }\end{array}$ & $\begin{array}{l}\text { Defining the local value in the functioning of } \\
\text { the acquired quality value system within the } \\
\text { global activity of the aggregate quality } \\
\text { system }\end{array}$ \\
\hline 6. & $\begin{array}{l}\text { Efforts are not focused on any specific } \\
\text { geographical region; each subsidiary operates } \\
\text { according to the terms of its market. }\end{array}$ & $\begin{array}{l}\text { Corporate QMS needs to issue directives and } \\
\text { possess enforcement powers; quality managers in } \\
\text { subsidiaries are held accountable to HQ. }\end{array}$ & $\begin{array}{l}\text { Development of a global identity that sees the } \\
\text { unique value of each local or acquired quality } \\
\text { system within the global quality system }\end{array}$ \\
\hline 7. & $\begin{array}{l}\text { Efforts are made to expand the company's } \\
\text { market share because of intense attention to the } \\
\text { customers' needs. }\end{array}$ & $\begin{array}{l}\text { Quality managers within the group are not in } \\
\text { continuous contact but should have a joint forum and } \\
\text { some degree of coordination and general guidelines } \\
\text { about best practices for methods and processes. }\end{array}$ & \\
\hline
\end{tabular}

Column 1 of the table presents the strategic, operational, and marketing characteristics that emerged from mapping the structure of the multinational companies participating in the study and the relevant professional literature. Column 2 of the table represents the desired theoretical profile (the ideal response) of the QMS to these needs and characteristics (local and global). This profile was initially broadly constructed by Bashan and Notea] who discuss regulation of local and global needs of the quality system resulting from global expansion measures [22]. The presentation of the theoretical QMS profile constitutes an interpretation and attempt to evaluate relevant response channels of the quality system for these needs, as emerged from the field research findings in 18 multinational companies (see the methodology chapter). Column 3, which the researchers developed, establishes and deepens the theoretical profile of the desired quality system (in column 2) while creating the emphases and responses to the dynamics of M\&A that challenge its operations and require a proper strategic response.

After outlining the general theoretical profile of the strategic, operational, and marketing characteristics (column 1), the desired QMS (column 2), and the specifics of the required functions of the QMS in the face of challenges of M\&A (column 3), the researchers described the gaps between them by analyzing the differences between the field research findings and the theoretical profile. This comparison provides a basis for presenting current adequacy levels of the quality systems' functioning in the field. These gaps/levels of adequacy are between the required theoretical functioning of $M \& A$, which is a significant challenge to their conduct. The process of analyzing the findings is displayed in Figure 2.

The researchers analyzed the field research findings from participating global organizations and identified applicable gaps between the practical function of quality systems and their theoretical functioning, as presented in column 3 . The analysis of the gaps identified focused on two main areas:

1) Developing appropriate coordination and control mechanisms by the parent company's headquarters and the local, acquired company to ensure effective connection.

2) Developing a global identity to define each quality system's functionality in its local space versus the global value it can provide or receive as a single unit, by integrating it into the parent company's overall quality system. These gaps exist in both the parent 
company's quality system level and the individual quality systems of the (acquired) subsidiaries themselves. To highlight the gaps between the parent and the local company, the analysis distinguishes between the needs of the parent company and the subsidiaries in the theoretical profile created.

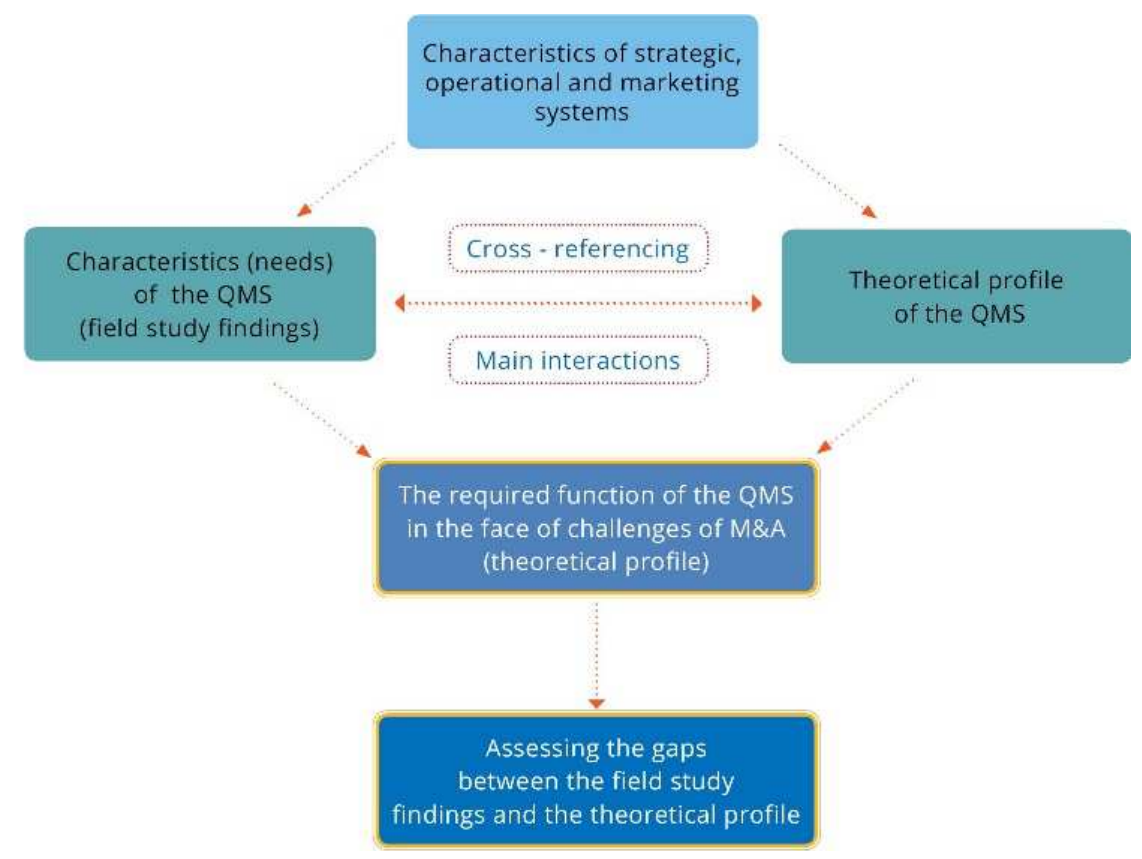

Figure 2. Cross-referencing process.

\subsection{Gaps in the Functioning of the Quality Systems of the Subsidiaries - with the Requested Theoretical Profile}

1) No consistent approach for integrating the acquired quality system into the existing quality system was identified. Slow quality system integration is required in order not to harm and impact its operations - but this is not always the case. In other cases, no change will be necessary. "In the case of companies in loss, the approach is to enforce prompt standardization and not give them the freedom to act."

2) The acquiring company's quality systems and organizational maturity level are significant factors in the standardization process.

3) A factor that can impact the integration is driven by a “customer's purchase of a 'mature organization,' which requires adapting internal processes to the customer's requirements in many cases."

4) The level of requirements from the quality system of the acquired company also depends on the quality manager himself. "If the company has compliant quality systems, there will be more rigorous requirements."

5) Integration of acquired quality systems ranges between providing high autonomy and enforcement of absolute standardization. The increased independence mainly characterizes the acquisition of a company from another industry (the hub is unlinked). Another alternative is to "harmonize," which means combining the two quality systems without extensive changes.

6) The maturity level of the quality systems in the group can be characterized by significant variance. Some acquired companies bring with them mature quality systems but some do not. "Sometimes it happens that a company is acquired and doesn't even have an ISO certificate."

7) The geographical area of the acquired company is also of great importance. In some countries and organizations, all actions are carried out individually (following the acquisition), classifying quality per risk, and examining all aspects.

8) There are relationships between the group's subsidiaries, such as vendor-customer relationships, common markets, competing companies (within the group), etc. Cooperation between the companies is also expressed through the use of complementary products and services developed by one subsidiary for the needs of others in the Group, and vice versa.

9) There is ambiguity regarding integrating an acquired local quality system into the cross-organization business processes of the multinational company. It should be taken into account that the dynamics of M\&A can continue simultaneously in both the parent company and a subsidiary, because each has its own subsidiaries and can continue acquiring other companies.

10)The quality system of the subsidiary is required to operate closely with the local operation and marketing teams (similar to how it acted before its acquisition). At the same time, it is necessary to integrate, adapt and respond to the guidance provided by the parent company and Corporate Quality. This collaboration will include business priorities, budget, operational effectiveness, and resources.

11)The quality system can often find itself isolated from 
its original suppliers and customers due to a central procurement policy required by Corporate Quality.

12)The subsidiaries' existing and acquired quality systems are exposed to the dynamic changes in the local market, and also to the dynamics of the requirements and guidelines required by Corporate Quality (policies, harmonization, and standardization) - arising from global interests of coordination and operational effectiveness.

13)The quality system operates and interacts with both local and global needs. The quality system is required to adapt and show flexibility against these changing needs. To function and meet the requirements within the local-global environment, the local level must adjust the dynamics of the market and its customers. At the same time, it must adapt to corporate requirements, mainly on issues related to operational efficiencies such as central procurement, etc.

14)There is uncertainty regarding the contribution of the local quality system to the company's global value and its integration with the group's other quality systems.

15)The relationships between the different quality systems in the group are usually unaligned. The dynamics of joining new quality systems in the group are accompanied by ambiguity regarding the "global identity" both in the newly-acquired company and the existing companies. The following quotations from interviews with quality managers in subsidiaries express the existing gaps:

a. "Sometimes within a week you buy a company in China, in Brazil... Each has hundreds of employees and another USA giant... for \$1 million.

b. "At the current level, there is no ongoing relationship between the quality managers in the group. This limited relationship also relates to the newly acquired company. While there is a forum of quality managers, nothing is binding - there are guidelines on methods and processes."

c. "Ensuring the same product and consistency between you and your 'partner company' can be difficult if the additional source, 'Your twin' does not report to you and does not coordinate with you."

d. "At the global quality management level, there are trials and moves, but not real things. There are specific initiatives and individual attempts to organize the business."

e. "The interaction in the field of quality management between the factories is extremely poor."

f. "The greater the differences between the factories and the smaller the similarity between the quality systems, the smaller the connection and the interaction between the organizations in the group."

16)There is awareness among the quality VPs and operations managers interviewed during the field study of the risk resulting from the lack of connection and coordination between quality systems (existing and acquired).

17)The study's findings indicate that the ability of subsidiaries or various operational units to produce uniform products, without coordination between them, is highly problematic. This is despite the process standardization implemented in some cases.

18)Mergers, acquisitions, and strategic partnerships create dynamics of change in forming network structure of the operational system. This is caused by the very existence or absence of strategic interactions, operational and marketing. As a result, there are quality systems that need to function at a high level of integration, maximum synchronization, and even the highest standardization level. Conversely, there are quality systems that be allowed to function with a high level of autonomy. The lack of communication with the different quality systems in the group is due to the significant variability between them.

19)The local quality system is required to range from "adaptive" to "proactive" (initiative, long-term vision).

20)Its proactivity is naturally limited to its functioning as a local system. Its connection to the other quality systems in the group is not dependent on the local quality system related to high-level strategic activities and initiatives driven by the broader organization. During the interview, the quality managers of the acquired companies suggested that there is usually no real connection.

21)The balance between adaptivity and proactivity of the individual quality system in the group of the subsidiaries should be managed and navigated by the parent company's quality corporate headquarters body. It should be backed by a clear concept and strategy, which are currently not available.

\subsection{Gaps in the Functioning of the Quality Systems of Corporate Quality}

1) The business environment is becoming increasingly complex, a multifaceted mix of companies, regions, business processes, business environments, and customers. Suppliers also merge, which makes managing complexity a key concept reflected in the functioning of functional systems at the headquarters, including the quality system. The main challenges of Corporate Quality are primarily focused on developing the appropriate integration mechanisms that will ensure that the different parts (the different quality systems) remain connected and function as a single organizational entity. This connection will enable the success of the quality of the products, services, and processes along the length and breadth of the multinational company.

2) The considerable effort invested in developing the appropriate integration mechanisms is still in its initiation phase. There is no defined approach by Corporate Quality on managing the quality system, which brings uncertainties regarding how to conduct integration.

3) The findings of the field study indicate low involvement of the global quality system at headquarters in strategic moves by the parent company. The lack of this functional involvement is reflected in 
the absence of assessments regarding the absorption a new quality system following M\&A processes.

4) In the early stages following the acquisition process, the parent company's tendency to maintain low involvement in the activity of the acquired subsidiary is notable. This low involvement is also reflected in the management activities of Corporate Quality at headquarters. "As long as the companies succeed, we'll keep letting them do what they know." They try not to shock them during initial stages after purchase, to allow for continued normal functioning.

5) In practice, a diverse mix of quality systems can be obtained. There are acquired companies that bring orderly quality systems with them but others do not. There may be quality systems certified to CMMI5 (due to historical customer requirements) but lack ISO certification within the same company. Following the purchase processes and the addition of companies and sites, different quality systems may not necessarily "talk to each other."

6) Over time, inner vision grows and attempts to integrate begin. Processes for "starting to work together" are initiated. After the "hug" stage, process of examining the possibility of integration commences. Corporate Quality attempts to develop a common language, thought teams and workgroups. "Uniform, clear and dictated standards for suppliers certification and a central mechanism for control of procurement costs begin to be created." There is a process towards more active control of quality systems operating in divisions and factories. The goal is to create "One Company" taking advantage of the aggregate ability of the Group's companies and, at the same time, maintaining the unique character of each subsidiary.

7) Following the M\&A dynamic, searches for an effective way to integrate (as described in the previous sections) appears, but the absence of a clear perception prompts integration based on economic rationale and increased operational effectiveness. In the field, possibilities for creating integrative activity of the various quality systems, based on shared resources are identified, to offset out-of-group spending, standardize procurement processes, and manage suppliers (for the benefits of scale created by central procurement). "The business and intuitive reality undoubtedly prevail. There's no clear strategy." The variance between the products and processes in the group makes it difficult to implement standardization and create a uniform quality system in the group. There are specific attempts by the parent company that are, in most cases, a process of continuous search and "trial and error" that reflect in a broad spectrum of conduct, from providing autonomy to enforcing standardization. A parent company's demand for standardization will require the subsidiary to "completely align" work processes, process management, standards, etc.

8) Not all companies have a Corporate Quality unit. This may reflect the low importance attributed to coordinating quality issues in the group (professional technicians are sufficient in some cases). The lack of Corporate Quality can lead to an unorganized process for integrating the local company quality system. In these cases, the collaboration between the quality systems is low, and there are few shared projects. The company can trigger cooperation and implementation of shared management processes.

9) Corporate Quality acts as a guiding body that is identified with and of great importance to companies with less developed quality systems (e.g., acquired companies in South America and elsewhere) "for which it can be really eye-opener due to their relatively low level. Regarding acquired companies from Europe or the United States, which function from the outset to high standards, it is less significant." That is, some acquired organizations need more support and guidance.

10)The absence of orderly integrative mechanisms that "connect" the company's quality system acquired to the group's other quality systems may jeopardize detection of counterfeit products and impair the level of consistency required.

11)Additional risks arising from the lack of a clear perception of how to integrate the quality systems of the acquired (and existing) companies into the group and stem from field studies:

a. Replication - Duplication and unnecessary tasks performed simultaneously on several sites.

b. Lack of coordination between parts resulting from cuts in the production process, working to different standards.

c. The remoteness of process managers due to a lack of communication.

d. Impaired transfer of knowledge: knowledge and experience accumulated over time are not transferred to the benefit of the employees and managers in the value of the other subsidiaries.

12)The difficulty in the aggregate management of the group's various quality systems, including the integration of the new, acquired quality systems into the Group's global quality management activity, increases as the company's international level of development (expansion) grows. The parent company finds it challenging to coordinate aggregate quality activity within innovative structures that characterize high levels of global development, such as network organizations, fragmented organizations, and a variety of strategic partnerships designed to increase the level of flexibility of the organizations. These structures express complex interactions based on diverse combinations of business processes, different types of collaborations, and a variety of connections to suppliers. Absent a clear perception regarding the aggregate management of the various quality systems, and because regulatory requirements are less likely to influence the behavioral patterns of Corporate Quality than the core of business in the 
international field, Corporate Quality becomes an adaptive body that is satisfied with the role of "harmonization" between the various quality systems, or a body that promotes and implements managerial approaches among the subsidiaries, with minimal involvement in strategic issues, including M\&A.

The study found that acquiring and merging companies do not sufficiently examine aspects related to the quality systems of the acquired companies. The challenges facing the parent company and the subsidiaries are expressed in various ways, between local interests and global interests, which must be realized by the parent company's Corporate Quality. The requisite level of integration is critical to global management but remains unclear because it is influenced by strategic, operational, and marketing interests.

\section{Discussion}

Globalization of the international economy and the subsequent changes in the workforce and technology have greatly influenced the development of the concept of quality around the world. These changes, taken together, necessitate adopting a new approach to defining quality. Corporate efforts to expand through M\&A further add to the increasing complexity and diversity of mutual relationships between global quality processes and business transactions.

M\&A and corporate expansion processes create network organizations in which synergy is generated between organizations or within a meta-organization. To depict global maturation of QMS, Bashan and Notea propose a hierarchical model for multinational organizations and derivative one for subsidiaries. A mature global QMS must be built on standardized processes that can be applied at all locations that are part of the MNC [21]. The QMS dictates the responsibilities, processes, and resources necessary for guaranteeing high-quality organizational activities [10]. Bashan and Kordova demonstrated the need for a systems approach in global quality management, which may help face QMS-related challenges [22].

The effectiveness of M\&A is influence by varied factors. Considerable research has considered the financial, strategic, operational, behavioral, and cross-cultural components of M\&A, with particular attending to financial and market aspects $[14,17,37,38]$.

The literature considers several models that potentially affect the results of M\&A. Some scholars content that the acquisition process, national culture, organizational practices and corporate culture are all essential parts in a successful M\&A transaction [39]. Others found that communications is a crucial factor for upgrading M\&A outcomes [40]. Steigenberger outlined a model for M\&A integration that is based on four-categories, none of which include the quality system as a factor in the success or failure of integration [41].

Analysis of the current findings identified existing gaps in the desired, theoretical profile created as the basis for this study that focuses on formulating a proactive perception of global quality systems' conduct when facing challenges and the companies' global expansion. This discussion chapter presents a proposed framework for supporting the dynamic development of multinational companies: mergers, acquisitions, strategic partnerships, and business models, in which companies use to achieve global competitiveness. The current findings indicate the absence of a relevant strategy, and the many challenges and dilemmas resulting from the global quality management level. This framework emphasizes creating effective integration mechanisms for integrating functional systems - which are dedicated to ensuring the quality of products and services along the length and breadth of inter-company processes that cross the organization and geographical areas. Figures 3 and 4 present the framework for combining effective QMS with M\&A that can drive successful outcomes of M\&A. This framework is an essential part of the future development of a global quality management strategy, strengthening the position of Quality at Corporate Headquarters as a global headquarters body involved in the company's strategic steps and at the core of international management.

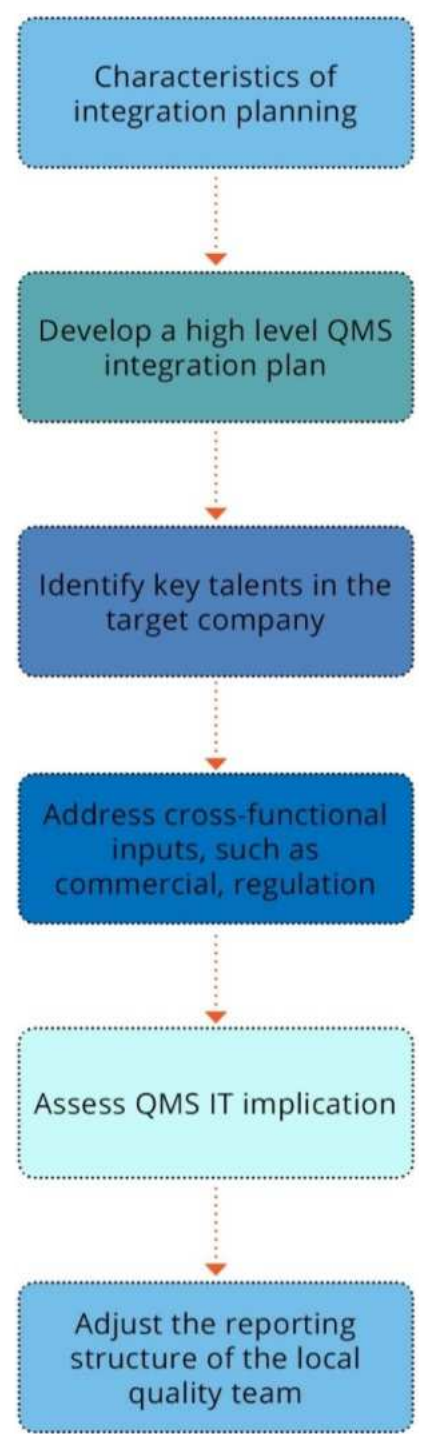

Figure 3. The framework for combining effective $Q M S$ with $M \& A-$ Integration Planning. 


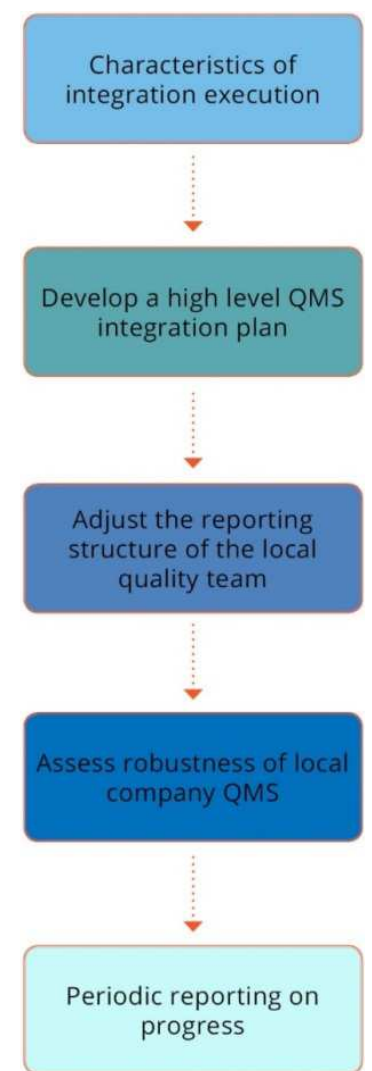

Figure 4. The framework for combining effective QMS with $M \& A-$ Integration Execution.

Many companies rely on M\&A as a quick way to accelerate innovation when the necessary technology does not exist internally. Since there were gaps in the previously existing methodology and process for M\&A, both internal and external, there is a need to develop a framework and process for executing M\&A. This framework will facilitate improving standardization across companies and thereby enhance the acquisition's efficiency and effective integration for innovation. It was created based on the gaps identified and proactive lessons learned, which are opportunities to improve QA within a M\&A process. In recent years, as the number of M\&As increased significantly, there has been a need to ensure consistency and maximize efficient use of resources across subordinate companies. Using the suggested framework can enable (1) integrating the acquired company more quickly, (2) enhancing customer satisfaction by providing better quality products and services to their respective clients, end-users, partners, and distributors, and (3) reducing waste by the better use of material, time and resources.

To drive an effective integration process, it is important to correctly identify potential gaps that may lead to compliance issues in the QMS once the acquisition is concluded. The following steps are used during this phase of integration planning:

1) While reviewing the status of the target company's QMS before the acquisition, the quality team develops a high-level QMS integration plan. This plan considers local governmental requirements, change management aspects, and mandatory QMS elements that must be integrated during the first year. This approach serves as a tool for not overwhelming the target company and for working together once the deal is finalized.

2) Prior to the acquisition, the acquiring company should assess if the target company would be a good fit within the acquiring company. This assessment includes identifying essential workers who should be retained in order to transfer knowledge. As part of planning and implementing integration, these resources are used to support not only the quality systems' integration but also transfer of knowledge from the local target QMS to the global organization QMS.

3) The global company must plan the integration steps carefully to ensure that their implementation does not disrupt service to clients, end-users, partners, and distributors. The commercial aspect is assessed to evaluate if extending the distribution footprint necessitates adapting the local company's QMS and expediting its integration into the global company QMS, in to comply with regional regulations.

4) Target companies are expected to use the global QMS IT software of the global company once the deal is finalized. Therefore, appropriate QMS software should be included when assembling the integration plan and timelines, in order to ensure that all aspects - including budget, timing, resources - are evaluated before committing to due dates. In cases where the target company already uses IT software, the integration plan should describe the phases for transitioning to the global company's software and decommissioning the current software.

5) The integration plan is typically a multi-year plan, for the period between closure of the deal and completion of the target company's integration into the global QMS of the acquiring company. This integration plan lists the quality management elements and uses a risk-based approach for categorizing the priority of integrating these elements. One of the first actions take once the acquisition is finalized is changing the reporting structure of the local quality team (see the section on implementation, below).

While the framework emphasizes the importance of planning integration effectively, execution of the plan is also very important. The implementation phase includes the following steps:

1) The operational integration plan is created in a manner that avoids disrupting clients, end-users, partners, and distributors. It is essential to balance the speed of operational integration with the target company's daily activities and transition from a small or medium company into a global company. As a result, some of the acquired company's local operating activity is retained and integrated into the global company at the time specified in the integration plan.

2) One of the first actions take once the acquisition is 
finalized is changing the reporting structure of the local quality team. The local quality team starts reporting to the corporate quality team upon signing on the deal. Via multiple communication and touch-points, the local team is introduced to the global team and receives guidance on keeping the corporate quality team informed on the day-to-day activities and areas requiring improvement.

3) The target company is integrated in phases that take multiple factors into account. Once the acquisition is finalized, the global company conducts a quality audit to identify potential risks. The outcome of this audit is used as input for the integration plan. As part of the due diligence phase, the quality team develops a high-level integration plan that includes business aspects, to ensure that clients, end-users, partners, and distributors do not suffer disruptions. Business prioritization, such as the commercial launch of products in global regions, may also trigger operational integration changes, requiring compliance with region-specific regulations. Other factors impacting the operational integration plan and timelines are the QMS applicable software to ensure that all aspects such as budget, timing, resources are evaluated before committing to due dates.

4) A dashboard is used to monitor progress while implementing integration and issue periodic reports on that progress. This dashboard considers multidisciplinary aspects such as finance, tax, regulatory clearance, commercial readiness, supply chain, quality, and more. The quality metrics use the integrated QMS procedure.

\section{Conclusion and Directions for Future Research}

The dynamics of global company development via the mergers, acquisitions, strategic partnerships, and business models, which are used by companies to enhance their global competitiveness, have a direct impact the global company's quality objectives. The company must develop a strategy that is appropriate for the company's level of globalization and include effective integration mechanisms that combine the activities of its various functional systems and, of course, the quality system - all while continuing to create global value.

The main benefits of developing and implementing the proposed guiding framework are:

1) Identifying strategic, operational, and marketing interactions in the global (multi-site) quality system operation.

2) Mapping the needs of the quality system on both the local and global levels and developing a framework for their regulation and achievement of global value.

3) Developing local and global capabilities of the network-based quality system.

4) Developing quality support programs for strategic, marketing, and operational goals as a proactive-dynamic factors that provide value and develop capabilities for improving the quality of products and services (Quality Value Adding)

5) Consulting and assistance in developing a quality strategy that is derived from and supports the company's overall strategy.

6) Strengthening the global identity of the quality system and strengthening the strategic, operational, and marketing rationale for the way it works.

7) Enhancing the status of the Corporate Quality at headquarters as a global headquarters body, involved in the company's strategic steps and at the core of international management.

Directions for further research

This study lays the groundwork for future research to evaluate and generalize the strategic approach to quality management in global organizations. The ability to effectively integrate global QMS with M\&A, with integration planning and implementation, may result in improved M\&A outcomes. For future research, we recommend:

Running simulations to confirm the proposed principles of the model at different levels of globalization of operating systems and quality systems (varied configurations).

Developing indicators that organizations can use to check their condition at any given moment, and measure levels of improvement achieved after implementing the proposed methodology (information flow indices, distance indices, information transfer indices).

Using an objective quantitative method (statistical analysis of questionnaires) to evaluate the use of methodology among a large number of organizations.

Mapping additional variables that can assist in the integrative functional management of the quality system, including variables representing different organizational structures that can influence the aggregate management method of the global quality system.

Evaluative studies regarding the level of use for the proposed guiding framework among multinational companies at different levels of global development, as presented in the study.

Improving inclusion of the proposed guiding framework for managing additional functional systems such as global operations, global human resources, global marketing, etc.; developing an implementation model for methodology and tools for evaluating their application.

Expanding the process approach underlying the proposed model and extending the global quality system's responsibility for their coordination and overall effective management of a branched "inter-social" process set (between subsidiaries, strategic partners, etc.), which raises the need for further research to examine implementation of the suggested framework, within accepted models for quality assessment in organizations such as ISO 9001, Malcolm Baldrige's excellence model, EFQM's excellence model, and others.

Developing a computerized tool for mapping the various configurations of the networked operating systems, which 
characterize a multinational company. This mapping should provide a view of the interactions and connectivity between them (strategic connectivity, operational connectivity, marketing connectivity) and identify the key groups containing hubs that control a broad network of interactions. This computerized tool should be designed to support the coordination of the interdependence between quality systems, within the identified key groups (global functional integration of the quality system) and the development of their global capabilities, on a network basis.

\section{References}

[1] Mehra, S., Hoffman, J. M., \& Sirias, D. (2001). TQM as a management strategy for the next millennia. International Journal of Operations \& Production Management, 21 (5/6): 855-876.

[2] Srinivasan, A., \& Kurey, B. (2014). Creating a culture of quality. Harvard Business Review, 92 (4): 23-25.

[3] Eckardt, R., \& Skaggs, B. C. (2018). Service diversification and growth of professional service firms. Long Range Planning, 51 (1): 111-126.

[4] Hitt, M., Li, D., \& Xu K. (2016). International strategy: from local to global and beyond. Journal of World Business, 51 (1): $53-73$

[5] Kim, K. Y. (1995). Global quality management: a research focus. Decision Sciences, 26 (5): 561-569.

[6] Yu, Y., \& Huo, B. (2018). Supply chain quality integration: relational antecedents and operational consequences. Supply Chain Management: An International Journal, 23 (3): 188-206.

[7] Bihi, T., Luwes, N., \& Kusakana, K. (2018). Innovative quality management system or flexible manufacturing systems. 2018 Open Innovations Conference (OI). Johannesburg: 40-46.

[8] Weckenmann, A., Akkasoglu, G., \& Werner, T. (2015). Quality management: history and trends. TQM Journal, 27 (3): 281-294.

[9] Sadeghi Moghadam, M. R., Safari, H., \& Yousefi, N. (2021). Clustering quality management models and methods: systematic literature review and text-mining analysis approach. Total Quality Management \& Business Excellence, 32 (3): 241-264.

[10] Schönreiter, I. M. (2018). Methodologies for process harmonization in the post-merger integration phase: A literature review. Business Process Management Journal, 24 (2): 330-356.

[11] Farhan, A., Aneeta, M., \& Shafique, A. (2018). Merger \& acquisition strategy for growth, improved performance, and survival in the financial sector. Journal Perspektif Pembiayaan Dan Pembangunan Daerah, 5 (4): 196-214.

[12] Haeruddin, M. I. M. (2017). Mergers and acquisitions: quo vadis? Management, 7 (2): 84-88.

[13] IMAA. (2020). The institute for mergers, acquisitions and alliances. Available at: https://imaa-institute.org/mergers-and-acquisitions-statistics/ (accessed March 31, 2021).
[14] Ben Jacob, A. (2020). Mergers and acquisitions: a qualitative study in the medical device sector. International Journal of Management, Economics and Social Sciences, 9 (3): 161-181.

[15] Ahmed, I. (2019). Staff well-being in high-risk operating room environment: Definition, facilitators, stressors, leadership, and team-working: a case-study from a large teaching hospital. International Journal of Healthcare Management, 12 (1): 1-17.

[16] Fine, M. B., Gleason, K. \& Budeva, D. (2016). Getting what you're worth: implications that affect firm value in a brand acquisition. Journal of Brand Management, 23 (5): 70-96.

[17] Bhagwan, V., Grobbelaar, S. S., \& Bam, W. G. (2018). A systematic review of the due diligence stage of mergers and acquisitions: Towards a conceptual framework. South African Journal of Industrial Engineering, 29 (3): 217-234.

[18] Tripathi, V., \& Lamba, A. (2015). What drives cross-border mergers and acquisitions? A study of Indian multinational enterprises. Journal of Strategy and Management, 8 (4): 384-414.

[19] Bashan, A., \& Armon, D. (2019). Quality management challenges in a dynamic reality of mergers, acquisitions and global expansion. International Journal of Quality \& Reliability Management, 36 (7): 1192-1211.

[20] Kafetzopoulos, P., Psomas, L., \& Gotzamani, D. (2015). The impact of quality management systems on the performance of manufacturing firms. International Journal of Quality \& Reliability Management, 32 (4): 381-399.

[21] Bashan, A., \& Notea, A. (2018). A hierarchical model for quality management systems in global organizations. International Journal of Quality \& Reliability Management, 35 (7): 1380-1398.

[22] Bashan. A., \& Kordova, S. (2021). Globalization, quality and systems thinking: integrating global quality management and a

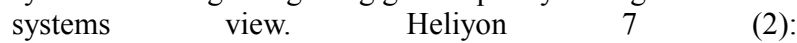
https://doi.org/10.1016/j.heliyon.2021.e06161 (accessed 19 July 2021).

[23] Edmondson, A. C., \& McManus, S. E. (2007). Methodological fit in management field research, Academy of Management Review, 32 (4): 1155-1179.

[24] Glaser, B. G., \& Strauss, A. L. (2017). Discovery of grounded theory: strategies for qualitative research. New York, NY: Routledge.

[25] Peshkin, A. (1993). The goodness of qualitative research. Educational Researcher, 22 (2): 23-29.

[26] Corbin, J., Strauss, A., \& Strauss, A. L. (2014). Basics of qualitative research: techniques and procedures for developing grounded theory. Thousand Oaks, CA: Sage Publications.

[27] Connelly, F. M., \& Clandinin, D. J. (1990). Stories of experience and narrative inquiry. Educational Researcher, 19 (5): $2-14$.

[28] Chun Tie Y., Birks M., \& Francis K. (2019). Grounded theory research: A design framework for novice researchers. SAGE Open Medicine. 7: 1-8.

[29] Ward, K., Gott, M., \& Hoare, K. (2017). Analysis in grounded theory: how is it done? Examples from a study that explored living with treatment for sleep apnea. Sage Research Methods Cases, Part 2. https://www.doi.org/10.4135/9781473989245 (accessed 19 July 2021). 
[30] Morrow, S. L. (2005). Quality and trustworthiness in qualitative research in counseling psychology. Journal of Counseling Psychology. 52 (2): 250-260.

[31] Sousa, D. (2014). Validation in qualitative research: general aspects and specificities of the descriptive phenomenological method. Qualitative Research in Psychology, 11 (2): 211-227.

[32] Gershenson, C., \& Heylighen, F. (2005). How can we think the complex? Managing Organizational Complexity: Philosophy, Theory and Application, 3: 47-62.

[33] Creswell, John. (1997). Qualitative inquiry and research design: Choosing among five traditions. Thousand Oaks, CA: Sage Publications.

[34] Lincoln, Y. S., \& Guba, E. G. (1985). Naturalistic Inquiry. Newbury Park, CA: Sage Publications.

[35] Sabar Ben-Yehoshua, N. (1997). Qualitative research in future prospective. In: Qualitative research, theory and practice: Aharon Shay \& Yehuda Bar-Shalom (Ed.). (pp. 17-25). Jerusalem: Modan Publishing [Hebrew].

[36] Yin, R. K. (2018). Case study research and applications: Design and methods. 6th ed. Thousand Oaks, CA: Sage.

[37] Bari, M. W., Fanchen, M., \& Baloch, M. A. (2016). Management practices and performance of mergers and acquisitions in Pakistan: Mediating role of psychological $\begin{array}{lllll}\text { contract. Springer Plus, } 5 & (1), & 1-16 .\end{array}$ https://doi.org/10.1186/s40064-016-3184-3

[38] Cartwright S., \& Schoenberg, R. (2006). Thirty years of mergers and acquisitions research: recent advances and future opportunities. British Journal of Management, 17 (S1): 81-85.

[39] Rottig, D., Schappert, J., \& Starkman, E. (2017). Successfully managing the sociocultural integration process in international acquisitions: A qualitative analysis of Cano's acquisition of Océ. Thunderbird International Business Review, 59 (2), 187-208. https://doi.org/10.1002/tie.21831
[40] Friedman, Y., Carmeli, A., Tishler, A., \& Shimizu, K. (2016). Untangling micro-behavioural sources of failure in mergers and acquisitions: A theoretical integration and extension. International Journal of Human Resources Management, 27 (20), https://doi.org/10.1080/09585192.2015.1042003

[41] Steigenberger, N. (2017). The challenge of integration: a review of the M\&A integration literature. International Journal of Management Reviews, 19 (4): 408-431.

\section{Biography}

Aviva Bashan is a senior lecturer and faculty member at Afeka Tel Aviv Academic College of Engineering. Her areas of research include quality management in global organizations and operational/strategic management of multinational companies. She has published a number of books on subjects including operations and production management, quality management, and statistical process control. She has been a member of the ASQC since 2001. This article is based on her doctoral research conducted in the Department of Statistics, University of Haifa, Israel in 2007-2015. She later (2017-2020) conducted additional field studies to expand the research and substantiate the findings.

Alon Ben Jacob is a graduate of the College of Management and Technology at Walden University. He is a Quality Executive in a global organization. He has over 20 years of experience in the quality industry, managing international teams, and has resided in the USA for the last five years. His research and expertise areas include global quality management and strategic quality management in mergers \& acquisitions. He is a member of The American Society of Quality (ASQ), The National Society of Leadership and Success (NSLS), and is an acting board member of the National D.B.A Society. He given multiple papers at international conventions. 